\title{
Study on the Prevalence and Characteristics of Metabolic Syndrome in Women of Reproductive Age Group with Polycystic Ovarian Syndrome
}

\author{
${ }^{1}$ Rekha R Madusudhanan, ${ }^{2}$ Bindu Nambisan, ${ }^{3}$ Mayadevi Brahmanandan, ${ }^{4}$ Sreekumari Radha
}

\begin{abstract}
Introduction: Polycystic ovarian syndrome (PCOS) is an endocrine disorder affecting all age groups and presenting with myriad problems like menstrual irregularities, hirsutism, anovulatory infertility, and long-term complications like diabetes, cardiovascular problems, etc.
\end{abstract}

Aim: Study was aimed at finding the prevalence, characteristics, and various risk factors of metabolic syndrome (MS) in reproductive age group in our hospital.

Materials and methods: Using statistical table, a sample size of 131 was calculated and patients were recruited as per inclusion criteria. Polycystic ovarian syndrome was diagnosed by the American Society for Reproductive Medicine (ASRM)/ European Society of Human Reproduction and Embryology (ESHRE) criteria. After informed consent, a detailed history was obtained and physical examination was carried out to assess, body weight, height, body mass index (BMI), waist-hip ratio (WHR), and blood pressure (BP). Fasting blood glucose, triglycerides, and high-density lipoprotein (HDL) were measured for each woman

Results: Prevalence of MS in our study was $45.8 \% ; 26.7 \%$ of patients had a combination of increased waist circumference, raised triglycerides, and low HDL; $55.2 \%$ of patients had a fasting blood sugar (FBS) levels more than $100 \mathrm{mg} \%$. Age of the patient was a statistically significant risk factor of MS with $100 \%$ of patients in the age group of 35 to 39 presenting with $\mathrm{MC}$. Body mass index was also a statistically significant risk factor with $82.6 \%$ with $\mathrm{BMI}>30$ having MC. Other important risk factors include a WHR more than 0.95 , presence of diabetes in mother or sister, and presence of acanthosis; $71 \%$ of patients with WHR more than 0.95 had MC. Age of menarche, duration of menstrual cycles, and hirsutism showed no significant relationship.

Conclusion: An outstanding fact that emerged in this study was that $94 \%$ of women with PCOS had HDL values $<50 \mathrm{mg} / \mathrm{dL}$. And $58 \%$ had triglycerides more than $150 \mathrm{mg} / \mathrm{dL}$. Hence, lifestyle modification and early intervention will hopefully spare long-term complication of PCOS.

\footnotetext{
${ }^{1}$ Trainee, ${ }^{2,3}$ Assistant Professor, ${ }^{4}$ Associate Professor

${ }^{1-4}$ Department of Obstetrics and Gynecology, Government Medical College, Thiruvananthapuram, Kerala, India

Corresponding Author: Bindu Nambisan, Assistant Professor Department of Obstetrics and Gynecology, Government Medical College, Thiruvananthapuram, Kerala, India, Phone: +91914712528432, e-mail: bindu.nambisan1971@gmail.com
}

Keywords: Cardiovascular disease, Diabetes, Metabolic syndrome, Polycystic ovarian syndrome, Reproductive age group.

How to cite this article: Madusudhanan RR, Nambisan B, Brahmanandan M, Radha S. Study on the Prevalence and Characteristics of Metabolic Syndrome in Women of Reproductive Age Group with Polycystic Ovarian Syndrome. J South Asian Feder Obst Gynae 2017;9(4):341-347.

Source of support: Nil

Conflict of interest: None

Date of received: 5 October 2017

Date of acceptance: 6 December 2017

Date of publication: January 2018

\section{INTRODUCTION}

Polycystic ovarian syndrome was first described by Dr Irving Stein and Michael Leventhal in Chicago in 1935 referring to a condition suffered by women with menstrual dysfunction, obesity, hirsutism, and bilateral polycystic ovaries. ${ }^{1}$ Then, it was called as Stein-Leventhal syndrome. Now PCOS is known as a multifaceted heterogeneous disorder and it is the single most common endocrinopathy in women of reproductive age group with evidence showing that 6 to $8 \%$ of women worldwide are affected. ${ }^{2,3}$

At a joint consensus meeting of ASRM and the ESHRE held at Rotterdam in May 2003, a refined definition of PCOS was agreed, namely presence of any two of the following three criteria ${ }^{1}$ :

1. Oligo and/or anovulation (primary menstrual dysfunction is oligomenorrhea).

2. Clinical and/or biochemical evidence of hyperandrogenism (hirsutism-most common, others include acne, androgenic alopecia).

3. Polycystic ovaries as defined by ultrasonography with exclusion of other etiologies.

The morphology of polycystic ovary on ultrasonography is defined as an ovary with 12 or more follicles measuring 2 to $9 \mathrm{~mm}$ in diameter and/or increased ovarian volume, i.e., more than $10 \mathrm{~cm}^{3}$.

Other features of PCOS that do not form part of definition include hyperinsulinemia and insulin resistance, ${ }^{4}$ obesity, increased luteinizing hormone:follicle-stimulating 
hormone ratio more than 2 or 3 since they are prevalent in disorders other than PCOS.

Metabolic syndrome describes a condition characterized by decreased sensitivity of tissues to insulin. This leads to a cluster of systemic abnormalities with serious clinical consequences. The National Cholesterol Education Programme Adult Treatment Panel III (NCEP-ATP III) criteria define $\mathrm{MC}$ as presence of any three or more of the following criteria in females:

- Central obesity, waist circumference more than $100 \mathrm{~cm}$ in males; more than $88 \mathrm{~cm}$ in females.

- Elevated triglycerides more than or equal to $150 \mathrm{mg} \%$ or on drug treatment for this lipid abnormality.

- Reduced HDL cholesterol, less than $45 \mathrm{mg} \%$ in males, less than $50 \mathrm{mg} \%$ in females or on drug treatment for this abnormality.

- Hypertension: systolic BP (SBP) $>135 \mathrm{Hg}$ or diastolic $\mathrm{BP}(\mathrm{DBP})>85 \mathrm{~mm} \mathrm{Hg}$ or on drug treatment for hypertension.

- Elevated fasting plasma glucose more than or equal to $100 \mathrm{mg} \%$.

Other conditions that have been associated with MC include impaired vascular regulation, proinflammatory state, prothrombotic state, and endothelial dysfunction. The pathophysiology that may link the MC and PCOS is insulin resistance. There are limited studies that look into the prevalence of MC in women with PCOS. This is especially important in Indian scenario where it is estimated that the prevalence of coronary heart disease has assumed epidemic proportions. The mortality due to coronary heart disease in India in 2013 was estimated to be $29 \%$. Of the estimated 10.5 million deaths annually, cardiovascular disease accounts for $20.3 \%$ in men and $16.9 \%$ in women. ${ }^{5}$ Regarding diabetes, India has currently over 62 million diabetics. The prevalence of diabetes in Kerala is found to be around $20 \%$, more than twice the national average of $8 \%$. It is therefore, important to screen and treat high-risk groups early to prevent long-term consequences.

The present study is an attempt to find out the prevalence of MC in women with PCOS in our population and distribution of its various components. This will help us to plan effective lifestyle interventions in the target group.

\section{MATERIALS AND METHODS}

\section{Study Design}

This is a descriptive study conducted in the Department of Obstetrics and Gynecology, SAT Medical College Hospital, Thiruvananthapuram, Kerala, South India.

\section{Sample Size}

Sample size was calculated as follows: $\mathrm{N}=(1.96)^{2} \mathrm{pq} / \mathrm{z}^{2}$, where $\mathrm{p}=$ prevalence of $\mathrm{MC}$ in various studies in the literature

$\mathrm{q}=100-\mathrm{p}$

$\mathrm{z}=$ precision coefficient

The calculated sample size was 131 .

\section{Inclusion Criteria}

Patients of reproductive age group, i.e., 18 to 44 years diagnosed to have PCOS according to ASRM/ESHRE criteria.

\section{Exclusion Criteria}

- PCOS patients on oral contraceptive pills.

- PCOS patients on metformin.

- Other causes of menstrual irregularities like thyroid abnormalities and hyperprolactinemia.

\section{Methodology}

An institutional ethics committee clearance was obtained prior to the study. In all the subjects, after getting written informed consent, a detailed history was obtained and then physical examination was carried out to assess body weight, height, BMI, WHR, and BP. Fasting blood glucose, triglycerides, and HDL were measured. Oligomenorrhea was defined as infrequent and irregular episodes of bleeding more than or equal to 45 days. Hypomenorrhea was defined as regularly timed scanty episodes of bleeding. Amenorrhea is absence of periods for more than 3 months. Subjects were assessed for hirsutism by using modified Ferriman-Gallwey score. A score of $>8$ was taken as hirsutism. The NCEP-ATP III criteria were used to define MC when three or more of the criteria were present. Height was measured with the stadiometer correct to $0.1 \mathrm{~cm}$ with the subject standing with arms at sides, heels touching the rod with head held erect, and the plane passing through the lower border of orbit and Frankfurt plane parallel. Weight was measured with weighing machine corrected to $0.5 \mathrm{~kg}$. Machine was checked for zero error prior to each measurement. Waist circumference was measured at a point midway between costal margin and anterior superior iliac spine using a nonstretchable tape; hip circumference was taken at the greater trochanter on both sides. All measurements were corrected to nearest centimeters. BP was recorded in the right upper limb in the sitting position taken as an average of two measurements taken with a standard sphygmomanometer 30 minutes apart. Women were advised to report in a fasting state the next day and blood samples were obtained for fasting lipid profile and blood sugars, which were sent to our biochemistry lab for analysis. Percentage of women fulfilling the criteria for MC was calculated. 
Study on the Prevalence and Characteristics of Metabolic Syndrome in Women

Table 1: Duration of menstrual cycle

\begin{tabular}{cll}
\hline Duration of cycle & Frequency & Percentage \\
\hline $45-60$ & 62 & 47.3 \\
$60-90$ & 25 & 19.1 \\
$90-120$ & 22 & 16.8 \\
$>120$ & 22 & 16.8 \\
\hline Total & 131 & 100.0 \\
\hline
\end{tabular}

Statistical analysis was carried out by entering the data into the Excel spreadsheet data and analyzed by using Statistical Package for the Social Sciences II package.

\section{OBSERVATIONS AND RESULTS}

In this study period, 131 PCOS women were included. The following were the results in this study.

Age distribution: The maximum number of women was in the 25 to 29 age group, which constituted $43.5 \%$ ( $n=57$ ) followed by $33.6 \%$ in the age group of 20 to 24 years $(n=44)$. There were $17.6 \%$ women $(n=23)$ in the age group of 30 to 34 years and $5.3 \%$ women $(n=7)$ in the age group of 35 to 39 years.

Mean age at menarche and duration of cycle length: Mean age of menarche was 13 years in around $26 \%$ of women, 12 years in $24.4 \%$ women, and 14 in about $21.4 \%$ of women. The mean cycle length of the study group was 72.5 days. Among these, $47.3 \%$ had a cycle length of 45 to 60 days, $19.1 \%$ had 60 to 90 days cycle length, $16.8 \%$ had 90 to 120 days cycle length, and another $16.8 \%$ had a cycle length of more than 120 days (Table 1).

Presence of diabetes in mother/sister: Among 131 patients studied, 16 patients give history of diabetes in either mother or sister, which constituted $12.2 \%$.

Presence of irregular cycles in mother/sister: Irregular cycle was present in the family in only one case. In 130 cases, the cycles were regular.

Hirsutism: Among 131 patients, 7 of them scored more than 8 with modified Ferriman-Gallwey score which constituted $5.3 \%$.

Acanthosis nigricans: 54 women had acanthosis, which constituted $41.2 \%$.

Body mass index: The maximum number of patients, i.e., $38.9 \%$, was in the BMI category 20 to 29.9 which constitute the overweight group and $17.6 \%$ were in more than $30 \mathrm{BMI}$ categories which constitute obesity group according to the World Health Organization (WHO) guidelines. The WHO has given South Asian guidelines for anthropometric measurements considering distribution of fat with regard to BMI. According to this, BMI $>23$ $\mathrm{kg} / \mathrm{m}^{2}$ should be taken as increased risk and BMI>27.5 $\mathrm{kg} / \mathrm{m}^{2}$ as high risk for this population (Table 2).

Waist-hip ratio: $26.7 \%$ of the study population had a WHR more than $0.95,48.1 \%$ had a ratio between 0.90 and
Table 2: Distribution according to BMI

\begin{tabular}{lll}
\hline Body mass index & Frequency & Percentage \\
\hline$<20$ & 11 & 8.4 \\
$20-24.9$ & 46 & 35.1 \\
$25-29.9$ & 51 & 38.9 \\
$>30$ & 23 & 17.6 \\
\hline Total & 131 & 100.0 \\
\hline
\end{tabular}

Table 3: Metabolic syndrome parameters

\begin{tabular}{lllll}
\hline Parameters & & Frequency & Percentage & Total \% \\
\hline Waist circumference & $<88$ & 81 & 61.8 & 100 \\
& $>88$ & 50 & 38.2 & \\
Triglycerides & $<150$ & 55 & 42 & 100 \\
& $>150$ & 76 & 58 & \\
HDL & $>50$ & 7 & 5.3 & 100 \\
& $<50$ & 124 & 94.7 & \\
SBP & $<135$ & 126 & 96.2 & 100 \\
& $>135$ & 5 & 3.8 & \\
DBP & $<85$ & 112 & 85.5 & 100 \\
& $>85$ & 19 & 14.5 & \\
FBS & $<100$ & 96 & 73.3 & 100 \\
& $>100$ & 35 & 26.7 & \\
\hline
\end{tabular}

0.95 , and $22.1 \%$ had a ratio between 0.85 and 0.90 . Only $3.1 \%$ had a ratio less than 0.85 .

FBS level: In $42 \%(\mathrm{n}=55)$ women, FBS was less than $90,45.8 \%(n=60)$ women had sugar levels between 90 and 110 , and $12.2 \%(n=16)$ had sugar levels more than $110 \mathrm{mg} \%$; 35 women $(\mathrm{n}=26.7 \%)$ had FBS values of more than $100 \mathrm{mg} \%$.

Metabolic syndrome parameters: Table 3 summarizes MC parameters:

- Waist circumference: $38.2 \%(n=50)$ of the patients in the study had a waist circumference of more than $88 \mathrm{~cm}$ and $61.8 \%(\mathrm{n}=81)$.

- Triglycerides: Hypertriglyceridemia (>150) was present in $58 \%(n=76)$ of the patients in the study. In $42 \%$ $(n=55)$, triglyceride levels were $<150$.

- HDL: Low HDL levels among the subjects were the most striking feature of the study. Among the 131 patients who met the inclusion criteria of the study, 124 patients, i.e., $94.7 \%$, had HDL levels less than $50 \mathrm{~m} / \mathrm{dL}$ and 7 patients, i.e., 5.3\%, had HDL levels more than 50 .

- BP levels: $3.8 \%$ of the patients had SBP more than $135 \mathrm{~mm} \mathrm{Hg}$ and $14.5 \%$ of the patients had DBP more than $85 \mathrm{~mm} \mathrm{Hg}$.

- FBS: $26.7 \%(\mathrm{n}=35)$ of the patients had FBS level more than $100 \mathrm{mg} / \mathrm{dL}$ and $73.3 \%(\mathrm{n}=96)$ had FBS levels less than 100.

Prevalence of MC: The prevalence of MC in this study was found to be $45.8 \%(n=60)$. The distribution of various components of $\mathrm{MC}$ in $45.8 \%$ of the cases who had the 
Table 4: Distribution of various components of MS

\begin{tabular}{lll}
\hline Distribution & Frequency & Percentage \\
\hline HDL+DBP+FBS & 1 & 1.7 \\
TG+HDL+FBS & 12 & 20.0 \\
TG+HDL+DBP & 3 & 5.0 \\
WC+HDL+FBS & 4 & 6.7 \\
WC+HDL+DBP & 5 & 8.3 \\
WC+HDL+SBP & 1 & 1.7 \\
WC+TG+FBS & 1 & 1.7 \\
WC+TG+HDL & 16 & 26.7 \\
TG+HDL+DBP+FBS & 1 & 1.7 \\
TG+HDL+SBP+DBP & 1 & 1.7 \\
WC+HDL+DBP+FBS & 2 & 3.3 \\
WC+HDL+SBP+DBP & 1 & 1.7 \\
WC+TG+HDL+FBS & 9 & 15.0 \\
WC+TG+HDL+SBP & 1 & 1.7 \\
WC+TG+SBP+DBP+FBS & 1 & 1.7 \\
WC+TG+HDL+DBP+FBS & 1 & 1.7 \\
\hline Total & 60 & 100 \\
\hline
\end{tabular}

TG: Triglycerides; WC: Waist circumference

Table 7: Distribution of WHR in the NMS and MS group

\begin{tabular}{|c|c|c|c|c|c|c|}
\hline \multirow[b]{2}{*}{ WHR } & \multicolumn{2}{|c|}{$\begin{array}{c}\text { No metabolic } \\
\text { syndrome }\end{array}$} & \multicolumn{2}{|c|}{$\begin{array}{l}\text { Metabolic } \\
\text { syndrome }\end{array}$} & \multicolumn{2}{|c|}{ Total } \\
\hline & $n$ & $\%$ & $n$ & $\%$ & $n$ & $\%$ \\
\hline$<0.85$ & 3 & 75.0 & 1 & 25.0 & 4 & 100.0 \\
\hline $0.85-0.90$ & 20 & 69.0 & 9 & 31.0 & 29 & 100.0 \\
\hline $0.90-0.95$ & 38 & 60.3 & 25 & 39.7 & 63 & 100.0 \\
\hline$>0.95$ & 10 & 28.6 & 25 & 71.4 & 35 & 100.0 \\
\hline Total & 71 & 54.2 & 60 & 45.8 & 131 & 100.0 \\
\hline$\chi^{2}=13.45$ & & & $\mathrm{df}$ & & $p=0$ & \\
\hline
\end{tabular}

syndrome is summarized in Table $4 ; 26.7 \%$ of the cases had increased waist circumference, raised triglycerides, and low HDL; $55.2 \%$ of the patients had FBS levels more than 100.

Risk factors of MC: Age of the patient was a statistically significant risk factor for MC. A total of $100 \%$ of the patients in the age group 35 to 39 had MC and 52.2\% of the patients in the age group 30 to 34 had MC; $41 \%$ of the patients below the age of 29 had MC in the study (Table 5); $51 \%$ of the patients in the BMI category 25 to 29.9 had MC and 82.6 of the BMI category more than 30 had MC, making BMI a very important statistically significant risk factor for MC (Table 6). Waist-hip ratio more than 0.95 is a statistically significant risk factor for $\mathrm{MC} ; 71 \%$ of patients with WHR more than 0.95 had features of MC (Table 7); 16 out of 131 patients gave history of diabetes in mother or sister, of which 13 patients, i.e., $81.3 \%$, had $\mathrm{MC}$ and 3 patients did not have the syndrome. Hence, history of diabetes in mother or sister is a statistically significant risk factor for MC (Table 8). The relationship
Table 5: Age distribution of MS

\begin{tabular}{|c|c|c|c|c|c|c|}
\hline \multirow[b]{2}{*}{ Age } & \multicolumn{2}{|c|}{$\begin{array}{c}\text { No metabolic } \\
\text { syndrome }\end{array}$} & \multicolumn{2}{|c|}{$\begin{array}{l}\text { Metabolic } \\
\text { syndrome }\end{array}$} & \multicolumn{2}{|c|}{ Total } \\
\hline & $n$ & $\%$ & $n$ & $\%$ & $n$ & $\%$ \\
\hline $20-24$ & 27 & 61.4 & 17 & 38.6 & 44 & 100.0 \\
\hline $25-29$ & 33 & 57.9 & 24 & 42.1 & 57 & 100.0 \\
\hline $30-34$ & 11 & 47.8 & 12 & 52.2 & 23 & 100.0 \\
\hline 35-39 & 0 & 0 & 7 & 100.0 & 7 & 100.0 \\
\hline Total & 71 & 54.2 & 60 & 45.8 & 131 & 100.0 \\
\hline \multicolumn{3}{|c|}{$\chi^{2}=9.833$} & \multicolumn{2}{|c|}{$\mathrm{df}=3$} & \multicolumn{2}{|c|}{$p=0.020$} \\
\hline
\end{tabular}

Table 6: Distribution of BMI among MS

\begin{tabular}{|c|c|c|c|c|c|c|}
\hline \multirow[b]{2}{*}{$B M I$} & \multicolumn{2}{|c|}{$\begin{array}{c}\text { No metabolic } \\
\text { syndrome }\end{array}$} & \multicolumn{2}{|c|}{$\begin{array}{l}\text { Metabolic } \\
\text { syndrome }\end{array}$} & \multicolumn{2}{|c|}{ Total } \\
\hline & $n$ & $\%$ & $n$ & $\%$ & $n$ & $\%$ \\
\hline$<20$ & 10 & 90.9 & 1 & 9.1 & 11 & 100.0 \\
\hline $20-24.9$ & 32 & 69.6 & 14 & 30.4 & 46 & 100.0 \\
\hline $25-29.9$ & 25 & 49.0 & 26 & 51.0 & 51 & 100.0 \\
\hline$>30$ & 4 & 17.4 & 19 & 82.6 & 23 & 100.0 \\
\hline Total & 71 & 54.2 & 60 & 45.8 & 131 & 100.0 \\
\hline \multicolumn{3}{|c|}{$\chi^{2}=23.451$} & \multicolumn{2}{|c|}{$d f=3$} & \multicolumn{2}{|c|}{$p=0$} \\
\hline
\end{tabular}

Table 8: Diabetes in mother/sister

\begin{tabular}{|c|c|c|c|c|c|c|}
\hline \multirow{2}{*}{$\begin{array}{l}\text { Diabetes in } \\
\text { mother/sister }\end{array}$} & \multicolumn{2}{|c|}{$\begin{array}{l}\text { No metabolic } \\
\text { syndrome }\end{array}$} & \multicolumn{2}{|c|}{$\begin{array}{l}\text { Metabolic } \\
\text { syndrome }\end{array}$} & \multicolumn{2}{|c|}{ Total } \\
\hline & $n$ & $\%$ & $n$ & $\%$ & $n$ & $\%$ \\
\hline No & 68 & 59.1 & 47 & 40.9 & 115 & 100.0 \\
\hline Yes & 3 & 18.8 & 13 & 81.3 & 16 & 100.0 \\
\hline Total & 71 & 54.2 & 60 & 45.8 & 131 & 100.0 \\
\hline$\chi^{2}=9.226$ & & & $d f=$ & & $p=c$ & \\
\hline
\end{tabular}

Table 9: Distribution of acanthosis in MS

\begin{tabular}{lllllllll}
\hline & \multicolumn{2}{c}{$\begin{array}{c}\text { No metabolic } \\
\text { syndrome }\end{array}$} & & \multicolumn{2}{c}{$\begin{array}{c}\text { Metabolic } \\
\text { syndrome }\end{array}$} & & \multicolumn{2}{c}{ Total } \\
\cline { 2 - 3 } Acanthosis & $n$ & $\%$ & & $n$ & $\%$ & & $n$ & $\%$ \\
\hline No & 53 & 68.8 & & 24 & 31.2 & & 77 & 100.0 \\
Yes & 18 & 33.3 & & 36 & 66.7 & & 54 & 100.0 \\
\hline Total & 71 & 54.2 & 60 & 45.8 & & 131 & 100.0 \\
\hline$\chi^{2}=16.112$ & $\mathrm{df}=1$ & & & & & $p=0$ &
\end{tabular}

between acanthosis and development of MC was statistically significant; $66.7 \%$ of the patients with acanthosis had MC (Table 9).

Age of menarche and duration of menstrual cycle, history of irregular cycles in mother or sister, and presence of hirsutism were not found to be a statistically significant risk factor of $\mathrm{MC}$.

Using logistic regression age more than 30, BMI more than 25, WHR more than 0.9 , and acanthosis were found to be significant (Tables 10 to 12). 
Table 10: Risk factors for MS in PCOS women

\begin{tabular}{|c|c|c|c|c|c|c|c|c|c|c|c|}
\hline \multirow[b]{3}{*}{ Age $>30$} & \multicolumn{2}{|c|}{ No MS } & \multicolumn{2}{|c|}{$M S$} & & \multirow[b]{2}{*}{$\%$} & \multirow[b]{2}{*}{$\chi^{2}$} & \multirow[b]{2}{*}{$p$-value } & \multirow[b]{2}{*}{ OR } & \multirow{2}{*}{\multicolumn{2}{|c|}{$95 \% \mathrm{Cl}$}} \\
\hline & $N$ & $\%$ & $N$ & $\%$ & & & & & & & \\
\hline & 11 & 36.7 & 19 & 63.3 & 30 & 100 & 4.818 & 0.028 & 2.53 & 1.09 & 5.87 \\
\hline $\mathrm{BMI}>25$ & 29 & 39.2 & 45 & 60.8 & 74 & 199 & 15.434 & 0 & 4.35 & 2.05 & 9.22 \\
\hline WHR $>0.90$ & 48 & 49.0 & 50 & 51.0 & 98 & 100 & 4.268 & 0.039 & 2.40 & 1.03 & 5.56 \\
\hline Diabetes in mother/sister & 3 & 18.8 & 13 & 81.3 & 16 & 100 & 9.226 & 0.002 & 6.27 & 1.69 & 23.33 \\
\hline Acanthosis & 18 & 33.3 & 36 & 66.7 & 54 & 100 & 16.112 & 0 & 4.42 & 2.10 & 9.29 \\
\hline
\end{tabular}

OR: Odds ratio; $\mathrm{Cl}$ : Confidence interval

Table 11: Logistic regression

\begin{tabular}{llll}
\hline Step 0 variables age 30 & 4.818 & 1 & 0.28 \\
BMI 25 & 15.434 & 1 & 0 \\
WHR.9 & 4.268 & 1 & 0.039 \\
Diabetes & 9.226 & 1 & 0.002 \\
Acanthosis & 16.112 & 1 & 0 \\
Overall statistics & 35.624 & 5 & 0 \\
\hline
\end{tabular}

\section{DISCUSSION}

A clustering of abnormalities associated with insulin resistance was first described in 1988 by Reaven, ${ }^{6}$ who coined the term syndrome $X$, now named as MC. The prevalence for MC in PCOS is not defined although both have a common etiological factor: insulin resistance. Based on the association with insulin resistance and risks for cardiovascular disease and type II diabetes mellitus, one could hypothesize that there would be a greater prevalence of PCOS among women presenting with the $\mathrm{MC}$. Korhonen et $\mathrm{al}^{7}$ conducted a cross-sectional population-based study of 543 premenopausal women in Finland to evaluate the sex hormone profile of women with MC as defined by the ATP III criteria. Their result demonstrated that women with MC had significantly higher mean free testosterone levels, higher free androgen index, and lower insulin sensitivity compared with women without the MC, even if the former group did not exhibit all the defining characteristics of PCOS. Conversely, several studies have demonstrated a high prevalence of the $\mathrm{MC}$ in women with PCOS.

The prevalence of the MC in premenopausal women with PCOS ranges from 33 to $47 \%$. In a study done in 106 women with PCOS, Apridonidze et $\mathrm{al}^{8}$ reported a $43 \%$ prevalence rate. They also demonstrated that majority of women with PCOS present clinically with at least one component of MC. In the same study, $68 \%$ of women with PCOS had low HDL cholesterol. Other studies have demonstrated similar prevalence rates of the MC in PCOS. Glueck et $\mathrm{al}^{9}$ reported a $46 \%$ incidence of $\mathrm{MC}$ in a group of 138 women with confirmed PCOS. In a retrospective study of 129 women with PCOS and 177 normal controls, Dokras et a ${ }^{10}$ discovered that the age-adjusted prevalence
Table 12: Variables in the equation

\begin{tabular}{lllllll}
\hline & \multicolumn{3}{c}{ Standard } & & & \\
& $B$ & error & Wald & df & Sig. & Exp (B) \\
\hline Step age 30 & 1.087 & 0.496 & 4.812 & 1 & 0.028 & 2.966 \\
BMI 25 & 1.064 & 0.422 & 6.367 & 1 & 0.012 & 2.899 \\
WHR.9 & 1.097 & 0.537 & 4.170 & 1 & 0.041 & 2.996 \\
Diabetes in & 1.282 & 0.744 & 2.966 & 1 & 0.085 & 3.602 \\
mother/sister & & & & & & \\
Acanthosis & 1.400 & 0.430 & 10.596 & 1 & 0.001 & 4.054 \\
Constant & 2.613 & 0.608 & 18.491 & 1 & 0 & 0.073 \\
\hline
\end{tabular}

rate of the MC in women with PCOS was $47.3 \%$ compared with a $4.3 \%$ rate in controls.

Obesity, a key determinant of insulin concentrations, has an independent effect on the risk for MC in women with PCOS. In a study by Ehrmann et $\mathrm{al}^{11}{ }^{11}$ it was found that among their cohort of 394 women with PCOS, women in the highest quartile for BMI had a 14-fold increased chance of having the MC. Further, they found that women with PCOS who have a family history of diabetes meet a greater number of individual diagnostic criteria for the MC than women with a negative family history. An increased waist circumference and WHR are independently associated with the risk of coronary heart disease even after controlling for BMI, hypertension, diabetes, and hyperlipidemia. ${ }^{12}$ Central obesity associated with PCOS is possibly the single most important risk factor for the development of diabetes and cardiovascular disease. Weight reduction by diet and exercise is always recommended.

About $45.8 \%(60 / 131)$ of sampled women with PCOS met the criteria of MC in our study. The prevalence of MC in literature varies from 33 to $47 \%$. In various Asian studies, prevalence as high as $47 \%$ has been reported. In a study by Ramachandran et al using modified ATP III criteria, prevalence of $46.5 \%$ has been reported in urban Asian Indian women. ${ }^{13}$

The mean age of the patients was 26.9 years in our study with a standard deviation of 4.3 (age range from 20 to 39 years). Their mean BMI was $26 \mathrm{~kg} / \mathrm{m}^{2}$ with a range of 14.6 to $39.2 \mathrm{~kg} / \mathrm{m}^{2}$. About $38.2 \%$ of the women have waist circumference more than $88 \mathrm{~cm}$. 
In this study, in $58 \%$ of the women with PCOS (76/131), triglyceride levels were more than $150 \mathrm{mg} / \mathrm{dL}$. The mean triglyceride levels were $121.2 \mathrm{mg} / \mathrm{dL}$.

In our study, $94.7 \%$ of the women with PCOS (124/131) had HDL levels less than $50 \mathrm{mg} / \mathrm{dL}$. A low HDL level present in the majority of the patients with PCOS defines an important feature of MC, i.e., found in our population. The values of HDL range from minimum of $16 \mathrm{mg} / \mathrm{dL}$ to maximum of $61 \mathrm{mg} / \mathrm{dL}$, with a mean value of $39.5 \mathrm{mg} / \mathrm{dL}$.

By considering BP measurements, 3.8\% had an SBP more than $135 \mathrm{~mm} \mathrm{Hg}$ and $14.5 \%$ had a DBP more than $85 \mathrm{~mm} \mathrm{Hg}$; $26.7 \%$ (35/131) of women with PCOS had elevated FBS levels.

\section{CONCLUSION}

The PCOS is the most common endocrine abnormality among women in the reproductive age group. MC clusters abnormalities that increase risk of diabetes and cardiovascular disease. In 2001, MC was noted as a legitimate cardiac risk factor and designated International Classification of Diseases-9 code of 277.7. Women with PCOS tend to meet many of the criteria of the MC. Women with PCOS present to the physician early because of problems like irregular menses, infertility, and hirsutism. The long-term consequences of PCOS are well known. Clinicians today must address the patient's immediate symptoms/concerns and must also be mindful of the potential long-term consequences including diabetes and cardiovascular diseases. In the general population also, MC is most common in women than in men. Diabetes and cardiovascular complications develop earlier and more frequently in women with PCOS. It is therefore, prudent to intervene in the prediabetes continuum and/ or prevent its development.

There are well-established guidelines to target diabetes and cardiovascular risk factors in all women. When a woman has PCOS, she needs additional surveys, thereby hopefully sparing long-term consequences.

\section{RECOMMENDATIONS}

- All women with PCOS attending the clinics for complaints of irregular periods, hirsutism, or infertility should be thoroughly evaluated and assessed for cardiovascular and diabetic risk factor. Physicians' approach must account for patient's goal as well as potential long-term consequences of the disease.

- All patients should be given information and education regarding the nature of the disease and should be motivated for regular follow-up.
Lifestyle modification including dietary recommendations and regular exercise forms a cost-effective and efficient management of PCOS. The adherence to programs of lifestyle change is very poor with high dropout rates. Hence, continuing psychological support and motivation from the part of clinician is crucial.

\section{ACKNOWLEDGMENTS}

Authors would like to thank Dr Nirmala C, Professor and Head of the Department of Obstetrics and Gynaecology, for her help in the selection of the topic and support during the study. The authors also extend their sincere thanks to Dr Saboora Beegum M, Professor and Head of the Department of Biochemistry, and Dr Roshni H Babu, postgraduate student of the Department of Biochemistry for the help with the investigations in this study. They are also thankful to Dr Sheila Balakrishnan, Associate Professor, Department of Obstetrics and Gynaecology, for her valuable suggestions during the study.

\section{REFERENCES}

1. Rotterdam ESHRE/ASRM-Sponsored PCOS Consensus Workshop. Revised 2003 consensus on diagnostic criteria and long-term health risks related to polycystic ovary syndrome (PCOS). Hum Reprod 2004;19(1):41-47.

2. Knochenhauer ES, Key TJ, Kahsar-Miller M, Waggoner W, Boots LR, Azziz R. Prevalence of the polycystic ovary syndrome in unselected black and white woman of the south eastern United States: a prospective study. J Clin Endocrinol Metab 1998 Sep;83(9):3078-3082.

3. Asunción M, Calvo RM, San Milián JL, Sancho J, Avila S, Escobar-Morreale HF. A prospective study in the prevalence of the polycystic ovary syndrome in unselected Caucasian woman from Spain. J Clin Endocrinol Metab 2008 Jul;85(7): 2434-2438.

4. Dunaif A. Insulin resistance and the polycystic ovary syndrome: mechanism and implications for pathogenesis. Endocr Rev 1997 Dec;18(6):774-800.

5. Gupta R, Mohan I, Narula J. Trends in Coronary Heart Disease Epidemiology in India. Annals of global health. 2016 MarApr;82(2):307-315.

6. Reaven GM. Banting lecture 1988. Role of insulin resistance in human disease. Diabetes 1988 Dec;37(12):1595-1607.

7. Korhonen S, Hippeläinen M, Vanhala M, Heinonen S, Niskanen L. The androgenic sex hormone profile is an essential feature of metabolic syndrome in premenopausal women: a controlled community-based study. Fertil Steril 2003 Jun; 79(6):1327-1334.

8. Apridonidze T, Essah PA, Iuorno MJ, Nestler JE. Prevalence and characteristics of the metabolic syndrome in women with polycystic ovary syndrome. J Clin Endocrinol Metab 2005 Apr;90(4):1929-1935.

9. Glueck CJ, Papanna R, Wang P, Goldenberg N, Sieve-Smith L. Incidence and treatment of metabolic syndrome in newly referred women with confirmed polycystic ovarian syndrome. Metabolism 2003 Jul;52(7):908-915. 
10. Dokras A, Bochner M, Hollinrake E, Markham S, Vanvoorhis B, Jagasia DH. screening women with polycystic ovary syndrome for metabolic syndrome. Obstet Gynecol 2005 Jul;106(1):131-137.

11. Ehrmann DA, Liljenquist DR, Kasza K, Azziz R, Legro RS, Ghazzi MN, PCOS/Troglitazone Study Group. Prevalence and predictors of the metabolic syndrome in women with polycystic ovary syndrome. J Clin Endocrinol Metab 2006 Jan;91(1):48-53.
12. Rexrode KM, Carey VJ,Hennekens CH, Walters EE, Colditz GA, Stampfer MJ, Willett WC, Manson JE. Abdominal adiposity and coronary heart disease in women. JAMA 1998 Dec;280(21):1843-1848.

13. Ramachandran A, Snehalatha C, Satyavani K, Sivasankari S, Vijay V. Metabolic syndrome in urban Asian Indian adults A population study using modified ATP III criteria. Diabetes Res Clin Pract. 2003;60:199-204 